International

Medical Society

http://imedicalsociety.org

\title{
Lamellar Keratoplasty in a Referral Center in Northeastern Brazil
}

\begin{abstract}
Ana Lúcia Dantas ${ }^{1}$, Sérgio Balbino da Silva ${ }^{1}$, Rita de Cássia Lira da Silva1, Luisa Alves Pereira de Aquino", Jéssica Valeska Herculano Lima1, Giovanna Karinny Pereira Cruz ${ }^{1}$, Priscila Fernandes Meireles ${ }^{1}$, Isabelle Campos de Azevedo ${ }^{1}$, Diana Paula de Souza Rego Pinto Carvalho", Allyne Fortes Vitor ${ }^{1}$, Viviane Euzébia Pereira Santos ${ }^{1}$, Marcos Antonio Ferreira Junior ${ }^{1}$
\end{abstract}

\section{Abstract}

Objective: To clinically characterize some cases of lamellar keratoplasty performed in a referral center of Rio Grande do Norte state.

Methods: This is a cross-sectional, retrospective study, which is the review of the medical records of 18 patients who underwent keratoplasty of lamellar type in a referral service in Natal/RN.

Results: It was found that of 18 patients who underwent keratoplasty, 55.56\% were male, being all patients with deep anterior lamellar. Regarding the age group, 66.67\% were thirty years old or less. The corneal vascularization of tissue was a factor receptor absent in $77.78 \%$ of cases. The main indication for lamellar keratoplasty were keratoconus (66.66\%). Of the cases in which transplantation was done with urgency, ocular diagnoses were not infectious ulcerative keratitis (50\%), corneal degeneration (25\%) and leukoma (25\%).

Conclusion: It is cocluded that the main indicator condition for lamellar keratoplasty was keratoconus. Patients who underwent the procedure were 30 years old or less, with minimum level of corneal vascularization and absence of glaucoma. Furthermore, the surgical technique predominantly used for lamellar transplantation was the deep lamellar keratoplasty due to its advantages over penetrating keratoplasty.
1 Department of Nursing, Federal University of Rio Grande do Norte, Natal, RN, Brazil.

Contact information:

Giovanna Karinny Pereira Cruz.

झ giovannakarinny@gmail.com

\footnotetext{
Keywords

Corneal Transplantation; Keratoplasty; Lamellar Keratoplasty; Corneal

Diseases, Keratoconus.
} 


\section{Introduction}

The keratoplasty or corneal transplant is the most frequently transplantation performed in the world and Brazil. It consists of a surgical procedure in which there is a substitution of an opaque cornea by a healthy donor cornea. This replacement may be all tissue layers (penetrant) or partial substitution only of the affected layer (lamellar) [1, 2].

For over a hundred years, corneal transplantation with total thickness (penetrating keratoplasty) was the only treatment option available to restore vision by corneal disorders. However, in the last decade, corneal transplantation was very fast developed from more selective forms of corneal layers, such as Deep Anterior Lamellar Keratoplasty (DALK) and lamellar keratoplasty Endothelial [3].

In these selective procedures of layers, only those ill are replaced, while the healthy ones are maintained. After the transition to the different procedures of lamellar transplantation and its continuous improvements, the visual results improved considerably, and the incidence of complications dropped significantly [3].

Corneal transplantation is subjected to high risk of failure associated with several determinants, such as its surgical technique, which may culminate in loss of visual sharpness, loss of quality of refraction and epithelialization disability. These events result of both the adverse effects of the underlying disease and immune rejection [2].

On the other hand, the survival of keratoplasty depends on several factors, and many of them are not fully understood. However, one of the most common causes of rejection is associated with endothelial failure surgical technique, which represents a substantial risk to the probability of graft survival, especially if not recognized and treated in time $[4,5]$.

The studies comparing the different lamellar and penetrating keratoplasty techniques have suggested important advantages when compared to the complications of penetrating techniques regarding the lamellar. These advantages include the ability to perform surgery in a closed system, with consequent reduction in the risk of expulsive hemorrhage, and significantly reduce the complications related to the suture, such as vascularization, infection, and post-trauma dehiscence in lamellar endothelial keratoplasty.

In this context, the aim of this study is to characterize clinically some cases of lamellar keratoplasty performed in a referral center of Rio Grande do Norte state.

\section{Methods}

It is a study of quantitative approach, cross-sectional, which is a case series about patients who underwent keratoplasty of the lamellar type, assisted by the ophthalmology sector of a referral service of Rio Grande do Norte state, from January 2010 to December 2014.

There are all procedures performed by the service during the study period using the technique of the lamellar type keratoplasty, 258 transplants involving addition to this technique, the penetrating type.

The case series are studies indicated to detect epidemic, features description of new diseases, hypothesis about possible causes of the diseases, description of the results of therapies and rare adverse effects in common diseases. The exact number of cases for the constitution of a series is divergent in the scientific literature, which may comprise three to ten cases, according to some authors and more than that according to other authors $[6,7]$.

For data collection of the cases secondary and constant sources in the medical records of patients were used assisted at the University Hospital Onofre Lopes (HUOL) of the Federal University of Rio Grande do Norte (UFRN) and the Bank of Ocular Tissues of Rio Grande do Norte, located in that hospital.

Data available from the patients of both genders and all ages, accompanied by the service during the study period were included in the sample, with me- 
dical indication confirmed to perform corneal transplantation by lamellar keratoplasty. Those with indication for penetrating keratoplasty and those who did not have all the information needed to reach the proposed goal were excluded. The final sample consisted of 18 patients. Data collection took place between January and April 2015.

The following clinical and epidemiological characteristics of cases were analyzed: gender, age, race, operated eye, surgical purpose, vascularization of the corneal tissue of the receiver, degree of vascularization, presence of glaucoma, ocular diagnosis, area that lives, middle region of the state prior, surgery, anterior corneal graft failure, eye classification, type of surgery and intraoperative complications.

The organization of data was using Microsoft Excel®. For descriptive analysis, absolute and relative frequencies by SPSS program, version 20.0 was used.

The research protocol of this study was approved by the Research Ethics Committee of the Federal University of Rio Grande do Norte in its ethical and methodological aspects, according to the resolution CNS 466/2012, an opinion 876, 177 and CAAE 37533014.8.0000.5537.

\section{Results}

To determine the characterization of cases of lameIlar keratoplasty, the records of 18 patients treated during the period studied in the Outpatient services and Ophthalmologic Surgical Center HUOL and the charts of surgical information available at the Eye Bank were reviewed.

Table 1 shows the clinical profile of these $18 \mathrm{pa}-$ tients who underwent keratoplasty; all were the type of Deep Anterior Lamellar Keratoplasty (DALK). Of the total, $55.56 \%(n=10)$ were male, brown and lived in the middle region of the Potiguar East. Regarding the age group, $66.67 \%(n=12)$ were thirty years old or less.
Table 1. Clinical and epidemiological characteristics of patients that underwent Deep Anterior Lamellar Keratoplasty. Natal/RN, Brazil, $2015(n=18)$.

\begin{tabular}{|c|c|c|}
\hline Characteristics & $\mathbf{N}$ & $\%$ \\
\hline \multicolumn{3}{|l|}{ Gender } \\
\hline Male & 10 & 55.56 \\
\hline Female & 8 & 44.44 \\
\hline \multicolumn{3}{|l|}{ Age group } \\
\hline Up to 20 years old & 5 & 27.78 \\
\hline 21 - 30 yers old & 7 & 38.89 \\
\hline 31 - 40 yers old & 1 & 5.56 \\
\hline 41 - 50 years old & 1 & 5.56 \\
\hline 51 - 60 years old & 1 & 5.56 \\
\hline Over 60 years old & 3 & 16.67 \\
\hline \multicolumn{3}{|l|}{ Race } \\
\hline Brown & 10 & 55.56 \\
\hline White & 7 & 38.89 \\
\hline Black & 1 & 5.56 \\
\hline \multicolumn{3}{|l|}{ Area who lives } \\
\hline Urban & 17 & 94.44 \\
\hline Rural & 1 & 5.56 \\
\hline \multicolumn{3}{|c|}{ Ocular diagnosis indicator } \\
\hline Keratoconus & 12 & 66.66 \\
\hline Corneal degeneration & 2 & 11.11 \\
\hline Interstitial keratitis & 2 & 11.11 \\
\hline Leukoma & 1 & 5.56 \\
\hline Other corneal & 1 & 5.56 \\
\hline \multicolumn{3}{|l|}{ Operated eye } \\
\hline Right & 11 & 61.11 \\
\hline Left & 7 & 38.89 \\
\hline \multicolumn{3}{|l|}{ Eye classification } \\
\hline Phakic & 17 & 94.44 \\
\hline Aphakic & 1 & 5.56 \\
\hline \multicolumn{3}{|l|}{ Vascularization } \\
\hline No & 14 & 77.78 \\
\hline Yes & 4 & 22.22 \\
\hline
\end{tabular}




\section{Characteristics}

N

$\%$

\section{Level of vascularization*}

\begin{tabular}{l|l|l|}
\hline Minimum & 2 & 50.00 \\
\hline Moderated & 1 & 25.00 \\
\hline Intense & 1 & 25.00 \\
\hline
\end{tabular}

\section{Glaucoma}

No

18

100.00

\begin{tabular}{|l|c|c|}
\hline Prior surgery & 17 & 94.44 \\
\hline No & 1 & 5.56 \\
\hline Yes & 13 & 72.22 \\
\hline Purpose & 5 & 27.78 \\
\hline Optical & & \\
\hline Tectonic & 14 & 77.78 \\
\hline Type of surgery & 4 & 22.22 \\
\hline Elective & & \\
\hline Urgency & 0 & - \\
\hline Intraoperative complications & & 100.00 \\
\hline Yes & 18 & $*$ : Absent data \\
\hline No & & \\
\hline
\end{tabular}

Of the cases studied, $72.22 \%(n=13)$ had optical purpose, with the presence of the lens at $94.44 \%$. The corneal vascularization of tissue factor receptor was absent in $77.78 \%$ of cases. All ocular diagnostics presented were classified according to the affected layer of corneal as stromal disorders.

The main indication for lamellar keratoplasty was keratoconus (66.66\%), followed by corneal degeneration and interstitial keratitis, both $11.11 \%$. Half of the cases presented a waiting list to perform the transplant of more than 136 days, or about four and a half months.

Cases whose transplant was performed on an urgency, ocular diagnoses were not infectious ulcerative keratitis (50\%), followed by corneal degeneration (25\%) and leukoma (25\%). All were classified as surgical emergency due to evolution of the perforation picture.

\section{Discussion}

Of the 258 transplants performed in the study period, only 18 were lamellar keratoplasty, of DALK type. They were performed in patients predominantly aged 30 years old or less, in phakic eyes, without the presence of factors associated with complications such as corneal vascularization, glaucoma, history of anterior surgery and/or complications during surgery.

The results showed that the main indicator condition for surgery in the study was keratoconus, a not inflammatory and progressive disease characterized by increased corneal curvature, with apical thinning and central corneal scarring. These changes often lead to reduced vision due to irregular astigmatism and central corneal scarring. [8]

The study showed that the technique of choice for surgical treatment of keratoconus was the deep anterior lamellar keratoplasty (DALK), presenting results similar to penetrating keratoplasty, however, with lower graft rejection rates.

This technique consists in the replacement of the receiver ill stromal by the donor stroma while the receiver corneal endothelium and Descemet's membrane are retained. This process enables a better preservation of the eye integrity and allows for early suture removal, as well as faster visual rehabilitation [9].

Concerning the advantages related to the surgical procedure of choice in transplant by penetrating keratoplasty technique (PK), it can occur rejection of all layers (epithelium, stroma, and endothelium) because it is a total thickness corneal graft.

However, Deep Anterior in Lamellar Keratoplasty (DALK), the preservation of healthy receiver endothelium is a major advantage since the rejection of endothelial allograft is virtually absent in these cases. This fact contributes significantly to the graft survival rates [9].

The prevalence of patients undergoing lamellar keratoplasty, aged thirty years old or less may be related to main indicator condition for the procedure, keratoconus. Such condition is developed during 
puberty or second decade of life, with continuous progression until the fourth decade of life before stabilizing. [10]

About this corneal vascularization in $22.22 \%$ $(n=4)$ of the cases, it is a factor that should be considered to be one of the complications of DALK due to surface and suture changes. Thus, a history of anterior vascular keratoplasty could represent a triggering factor for corneal opacification [11].

Another important fact is the glaucoma, characterized by being the leading cause of blindness after penetrating keratoplasty (PK), which leads to gra$\mathrm{ft}$ failure and irreversible damage of the optic disc caused by very high intraocular pressure. Although none of the cases submitted to DALK had glaucoma, eyes with a history of glaucoma, require monitoring for observation of intraocular pressure in early postoperative period. Studies have reported that increased intraocular pressure is a risk factor for endothelial cell loss after keratoplasty, in particular, the penetrating keratoplasty [12].

Of urgent cases whose deep anterior lamellar keratoplasty (DALK) was carried out, perforation was the main reason. The good results in keratoconus patients have led surgeons to use this technique in other conditions. Therefore, the information to perform DALK have expanded to other corneal ectasia, stromal dystrophies, scarring, stromal opacities, corneal ulcers and even cases of perforations [11].

The DALK offers significant advantage over PK in graft rejection and prevents long-term endothelial loss. Also, it provides a safe and effective therapy in the treatment of patients with corneal perforations and allows the preservation of the globe integrity and restoration of vision [13].

Meanwhile, the intraoperative corneal perforation, with aqueous shallow or output anterior chamber is often common condition that becomes necessary in some cases the change of the surgical technique for penetrating keratoplasty [13].

By the collected data and the analysis, it was found that the main condition indicator for lamellar keratoplasty was keratoconus, and the main reason was the emergency corneal perforation. Patients who underwent surgery were younger or equal to 30 years old, the level of corneal vascularization was minimal, and the presence of glaucoma was a missing factor in the study.

Moreover, the results showed that the lamellar technique predominantly used was the deep anterior lamellar keratoplasty (DALK), due to its advantages over penetrating keratoplasty (PK) as preservation of healthy endothelium and low graft rejection rates.

\section{Ackmowlegements}

The professionals of the Onofre Lopes University Hospital and the Bank of the Rio Grande do Norte Ocular Tissues that have contributed to carrying out the collection of data from this study.

\section{Financing}

Coordenação de Aperfeiçoamento de Pessoal de Nível Superior (CAPES) - Social Demand Program Scholarship.

\section{Conflicts of interests}

There were no conflicts of interest.

\section{References}

1. Brazilian Association of Organ Transplants. Brazilian Transplant Registry. Brazil, 2013.

2. Oliva MS, Schottman T, Gulati M. Turning the tide of corneal blindness. Indian J Ophthalmol. 2012; 60(5): 423-7.

3. Zeschau A, Balestrin IG, Stock RA, Bonamigo EL. Indications of keratoplasty: a retrospective study in a University Hospital. Rev Bras Oftalmol. 2013; 72(5): 316-20.

4. Wagoner MD, Ba-Abbad R, Al-Mohaimeed M, Al-Swailem S, Zimmerman MB. Postoperative complications after primary adult optical penetrating keratoplasty: prevalence and impact on graft survival. Cornea; 2009; 28(4): 385-94.

5. Kelly TL, Williams KA, Coster DJ. Corneal transplantation for keratoconus: a registry study. ArchOphthalmol. 2011; 129(6): 691-7. 
6. Parente RCM, Oliveira MAP, Celeste RK. Case Reports and Case Series in the Era of Evidence - Based Medicine. Bras. J. VídeoSur. 2012; p. 067-070.

7. Albrecht J, Meves A, Bigby M. Case reports and case series from Lancet had significant impact on medical literature. J ClinEpidemiol. 2005; 58(12): 1227-32.

8. Mascaro VLDM, Scaroi MJ, Hofling-Lima AL, Souza LB. Corneal transplantation in keratoconus: evaluation of results and complications obtained by skillful and surgeons in training. Arq. Bras. Oftalmol. 2007; 70(3): 395-405.

9. Dijk VKP, Baydoun L, Konder MR, Melles RJG. Contact lenses after keratoplasty. Contatct Lens Spectrum. 2014; 29: 36-42.

10. Abu-Amero KK, Helwa I, Al-Muammar A, Strickland S, Hauser MA, Allingham RR et. al. Case-control association between CCT-associated variants and keratoconus in a Saudi Arabian population. J Neg Res BioMed. 2015; 14: 1-8.

11. Feizi S. Deep anterior lamellar keratoplasty: indications, surgical techniques and complications. Middle East Afr J Ophthalmol. 2010; 17(1): 28-37.

12. Stewart RM, Jones MN, Batterbury M, Tole D, Larkin DF, Kaye SB. Effect of Glaucoma on Corneal Graft Survival acoording to indication for Penetranting Keratoplasty. Am J Ophthalmol. 2011; 151(2): 257-62.

13. Bhatt PR, Lim LT, Ramaesh K. Therapeutic deep lamellar keratoplasty for corneal perforations. Eye.2007; 21: 1168-73.

Publish in International Archives of Medicine

International Archives of Medicine is an open access journal publishing articles encompassing all aspects of medical science and clinical practice. IAM is considered a megajournal with independent sections on all areas of medicine. IAM is a really international journal with authors and board members from all around the world. The journal is widely indexed and classified Q1 in category Medicine. 